\title{
A Rapid and Semi-Quantitative Gold Nanoparticles Based Strip Sensor for Polymyxin B Sulfate Residues
}

\author{
Yue Li 1,2,3, Liqiang Liu 1,2,3, Shanshan Song ${ }^{1,2,3}$, Hua Kuang ${ }^{1,2,3, *}$ and Chuanlai Xu 1,2,3* \\ 1 State Key Laboratory of Food Science and Technology, Jiangnan University, Wuxi 214122, China; \\ liyuejiangnan@163.com (Y.L.); murel@163.com (L.L.); sss@jiangnan.edu.cn (S.S.) \\ 2 International Joint Research Laboratory for Biointerface and Biodetection, and School of Food Science and \\ Technology, Jiangnan University, Wuxi 214122, China; \\ 3 Collaborative Innovationcenter of Food Safety and Quality Control in Jiangsu Province, Jiangnan University, \\ Wuxi 214122, China \\ * Correspondence: kuangh@jiangnan.edu.cn (H.K.); xcl@jiangnan.edu.cn (C.X.); \\ Tel.: +86-510-85329077 (H.K.); +86-510-85329076 (C.X.)
}

Received: 8 February 2018; Accepted: 28 February 2018; Published: 5 March 2018

\begin{abstract}
Increasing attention is now being directed to the utilization of polymyxin B (PMB) as a last-line treatment for life-threatening infections caused by multidrug resistant Gram-negative bacteria. Unfortunately, polymyxins resistance is also increasingly reported, leaving a serious threat to human health. Therefore, the establishment of rapid detection methods for PMB residues is highly essential to ensure public health. In this study, two monoclonal antibodies (mAb; 2A2 and 3C6) were obtained using PMB-bovine serum albumin as the immunogen and PMB-ovalbumin as the coating antigen, which were prepared with $N-(\gamma$-maleimidobutyryloxy) succinimide ester and glutaraldehyde as cross-linking agents, respectively. Through an indirect competitive enzyme-linked immunosorbent assay, resultant two mAbs were compared and the results indicated that $3 \mathrm{C} 6$ showed higher sensitivity with a half maximum inhibition concentration of $13.13 \mathrm{ng} / \mathrm{mL}$. Based on 3C6, a gold nanoparticles (AuNPs)-based immunochromatographic test (ICT) strip was then established, the mechanism of which is that free PMB competes with the fixed coating antigen to combine with $\mathrm{mAb}$ labeled by AuNPs. Using ICT strip to detect milk and animal feed samples revealed the visible detection limits were $25 \mathrm{ng} / \mathrm{mL}$ and $500 \mu \mathrm{g} / \mathrm{kg}$, respectively and the cutoff limits were $100 \mathrm{ng} / \mathrm{mL}$ and $1000 \mu \mathrm{g} / \mathrm{kg}$, respectively. The ICT strip provides results within $15 \mathrm{~min}$, facilitating rapid and semi-quantitative analysis of PMB residues in milk and animal feed.
\end{abstract}

Keywords: polymyxin B; immunochromatographic test strip; gold nanoparticles; monoclonal antibody; milk; animal feed

\section{Introduction}

Polymyxin B (PMB), belonging to the family of polymyxins, is a lipopeptide antibiotic isolated from Paenibacillus polymyxa [1,2]. Structurally, it consists of a cyclic heptapeptide tripeptide side chain and a fatty acid tail (Figure 1) [3]. Although PMB possesses broad spectrum activity against many species of Gram negative bacteria by binding to the lipid A moiety of the bacterial lipopolysaccharide and subsequently disintegrating the bacterial membranes [4-6], it was unfavorable in the 1960s due to its toxic side effects, such as nephrotoxicity and neurotoxicity $[7,8]$. However, owing to the current inexorable emergence of multidrug resistant (MDR) Gram negative bacteria and the decline in newly developed antibiotics, PMB has been increasingly used clinically as a last resort drug for the treatment of MDR Gram negative bacterial infections [9-11].

Nevertheless, with the marked increase in usage of polymyxins to treat humans and animals, bacterial resistance has also increasingly emerged, leaving a global challenge in terms of polymyxins 
utilization [12-14]. Except for being utilized in the clinic, PMB is also used as a feed additive in animal husbandry to promote growth. However, at present, there is no maximum residue limit for PMB in animal-derived food products or animal feed nationally or internationally. Consequently, the abuse of PMB in animal food production has increased, resulting in a massive accumulation of PMB in animal-derived food products, which may put animals and ultimately, humans at risk for the acquisition of antimicrobial drug resistant pathogens [15]. Thus, to prevent this situation, the quantification of PMB in food and animal feed should be a focus of attention in terms of surveillance screening.

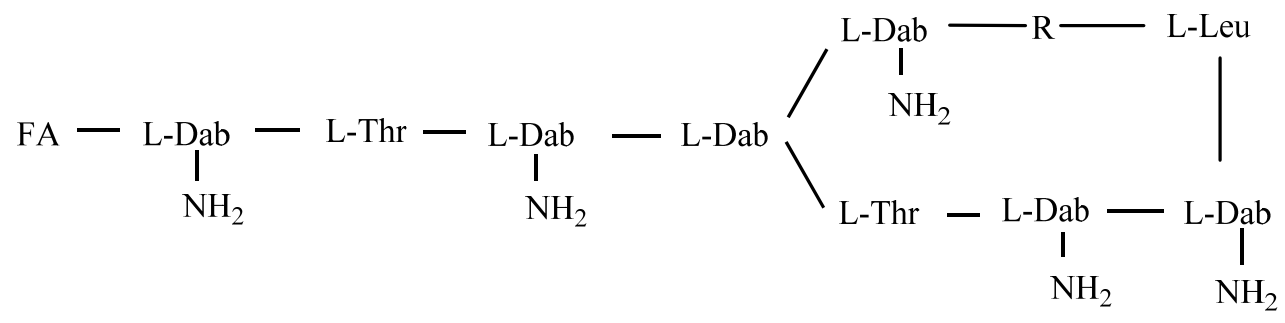

Polymyxin B: R = D-Phe

Polymyxin E: R = D-Leu

Figure 1. Chemical structures of polymyxin B and E.

PMB and polymyxin E (PME) only differ in a single amino acid residue within the heptapeptide ring (Figure 1) and are both used in clinical practice and animal production [3]. Commercially, PMB is available as a sulfate salt, a mixture of over 30 polypeptide species with the major components consisting of polymyxin B1, B1-1, isoleucine-polymyxin B1 (Ile-PMB1), B2, B3, B4, B5 and B6, differing in their fatty acid moiety [16]. PME is used as a sulfate salt or colistimethate sodium [2].

The most commonly used method for the quantification of PMB is currently chromatography. Several liquid chromatography tandem mass spectrometry methods have been developed for the quantification of: (i) polymyxin B1 and B2 in cation-adjusted Mueller-Hinton broth, human and rat plasma using protein precipitation extraction (PPE) for sample preparation [17]; (ii) polymyxin B1, B2 and B1-1 in human plasma and treated human urine utilizing solid phase extraction (SPE) for sample preparation [18]; (iii) polymyxin B1, B2, B3 and isoleucine-polymyxin B1 in human plasma, using trichloroacetic acid (TCA) and TCA-facilitated PPE [19]; and (iv) polymyxin B in bacterial growth media using PPE [20]. However, despite its sensitivity and accuracy, chromatography requires complex sample preparation, numerous organic solvents and expensive instruments, which restricts its wide-scale application. As an alternative, immunoassay is sensitive, simple and eco-friendly, as it is time saving, economical and does not require organic solvents. An enzyme-linked immunosorbent assay (ELISA) was established for the detection of PMB sulfate in human serum [21]. However, this assay only detected PMB sulfate in human serum samples and was not suitable for on-site analysis of $\mathrm{PMB}$ as a period of more than $3 \mathrm{~h}$ is required. Consequently, the development of a sensitive, rapid and reliable method is imperative for detection of PMB residues in animal-derived food products and animal feed samples.

Recently, the groundbreaking developments of nanoparticle-based biosensors offer many technological advances in food safety monitoring [22]. Nanoparticles are used commonly as labels for signal transduction and amplification [23,24]. Amongst nanoparticles, gold nanoparticles (AuNPs) are used most widely due to its strong adsorption and stability, which makes them suitable for ultrasensitive detection [25]. Yet, to our knowledge, no rapid and AuNPs-based analysis method for PMB has been reported for animal-derived food products and animal feeds. Therefore, in the present study, we prepared mouse-derived monoclonal antibodies against PMB with high sensitivity and 
specificity and established an AuNPs based immunochromatographic test (ICT) strip for the rapid and semi-quantitative analysis of PMB residues in milk and feed additive samples.

\section{Experimental Section}

\subsection{Reagents and Materials}

PMB and PME were purchased from J\&K Scientific Ltd. (Beijing, China). Bovine serum albumin (BSA), ovalbumin (OVA), $N$-[ $\gamma$-maleimidobutyryloxy] succinimide ester (GMBS), glutaraldehyde (GA), 3,3',5,5'-tetramethylbenzidine (TMB) and complete and incomplete Freund's adjuvants were obtained from Sigma-Aldrich (St. Louis, MO, USA). Horseradish peroxidase (HRP)-labeled goat anti-mouse immunoglobulin (IgG) was obtained from Jackson Immuno Research Laboratories (West Grove, PA, USA). Cell culture media were supplied by Life Technologies Corporation (Shanghai, China). Animal feed was purchased from Qinglongshan Laboratory Animal Co., Ltd. (Nanjing, China). All other reagents were purchased from the National Pharmaceutical Group Chemical Reagent Co., Ltd. (Shanghai, China).

Polyvinylchloride (PVC) backing card, glass fiber membrane, nitrocellulose (NC) membrane, sample pad (CB-SB08) and absorbent pad (SX18) were purchased from JieYi Biotechnology Co., Ltd. (Shanghai, China). The Dispensing Platform was obtained from Kinbio Tech Co., Ltd. (Shanghai, China).

All buffer solutions were prepared with ultrapure water (Milli-Q purification system, Millipore Co., Bedford, MA, USA).

\subsection{Synthesis of PMB-Protein Conjugates}

PMB was coupled to BSA with GMBS as a cross-linker according to a modified procedure previously described (Figure 2) [21,26]. In brief, $14 \mathrm{mg}$ of PMB in $1.5 \mathrm{~mL} 0.1 \mathrm{M}$ phosphate-buffered saline (PBS) ( $\mathrm{pH}=7.4)$ was added to GMBS $(2.8 \mathrm{mg})$, dissolved in $0.5 \mathrm{~mL}$ tetrahydrofuran and stirred for $30 \mathrm{~min}$ at $30{ }^{\circ} \mathrm{C}$. Following nitrogen gas treatment, the resulting mixture was washed three times using ether:methylene chloride $(2: 1, v / v)$ to remove excess GMBS to obtain solution A. Ten mg of BSA was dissolved in $0.2 \mathrm{~mL} 0.1 \mathrm{M}$ PBS and added to $50 \mu \mathrm{L} 0.5 \mathrm{M}$ hydroxylamine. After stirring for $10 \mathrm{~min}$ at $25^{\circ} \mathrm{C}$, the mixture was diluted with $3 \mathrm{~mL}$ of $0.1 \mathrm{M}$ PBS (containing $3 \mathrm{M}$ urea) to obtain solution B. Subsequently, solution B was immediately added to solution A and vigorously stirred at room temperature for $30 \mathrm{~min}$. The resultant mixture was dialyzed against $0.01 \mathrm{M}$ PBS for 3 days. The resulting solution was utilized as the immunogen and defined "PMB-GMBS-BSA." Similarly, the conjugate of PMB and OVA, used as the coating antigen, was prepared using the same method and defined "PMB-GMBS-OVA."

Another coating antigen was synthesized with GA as the cross-linker (Figure 2) $[27,28]$ and labeled "PMB-GA-OVA1." Briefly, $14 \mathrm{mg}$ of PMB and $48 \mu \mathrm{L}$ of $2.5 \%$ GA were subsequently dissolved in $200 \mu \mathrm{L}$ of ultrapure water. After mixing at room temperature for $2 \mathrm{~h}$, the activated solution was added dropwise into $1 \mathrm{~mL}$ of a stirred solution of $5 \mathrm{mg}$ of OVA in $0.01 \mathrm{M}$ PBS (pH = 7.4) and stirred for $4 \mathrm{~h}$ at room temperature. Following the same procedure, PMB-GA-OVA2 was prepared by changing $0.01 \mathrm{M}$ PBS to $0.01 \mathrm{M}$ MES ( $\mathrm{pH}=5.6$ ) to dilute OVA. The resultant mixtures were dialyzed as above and then stored at $-20^{\circ} \mathrm{C}$. 


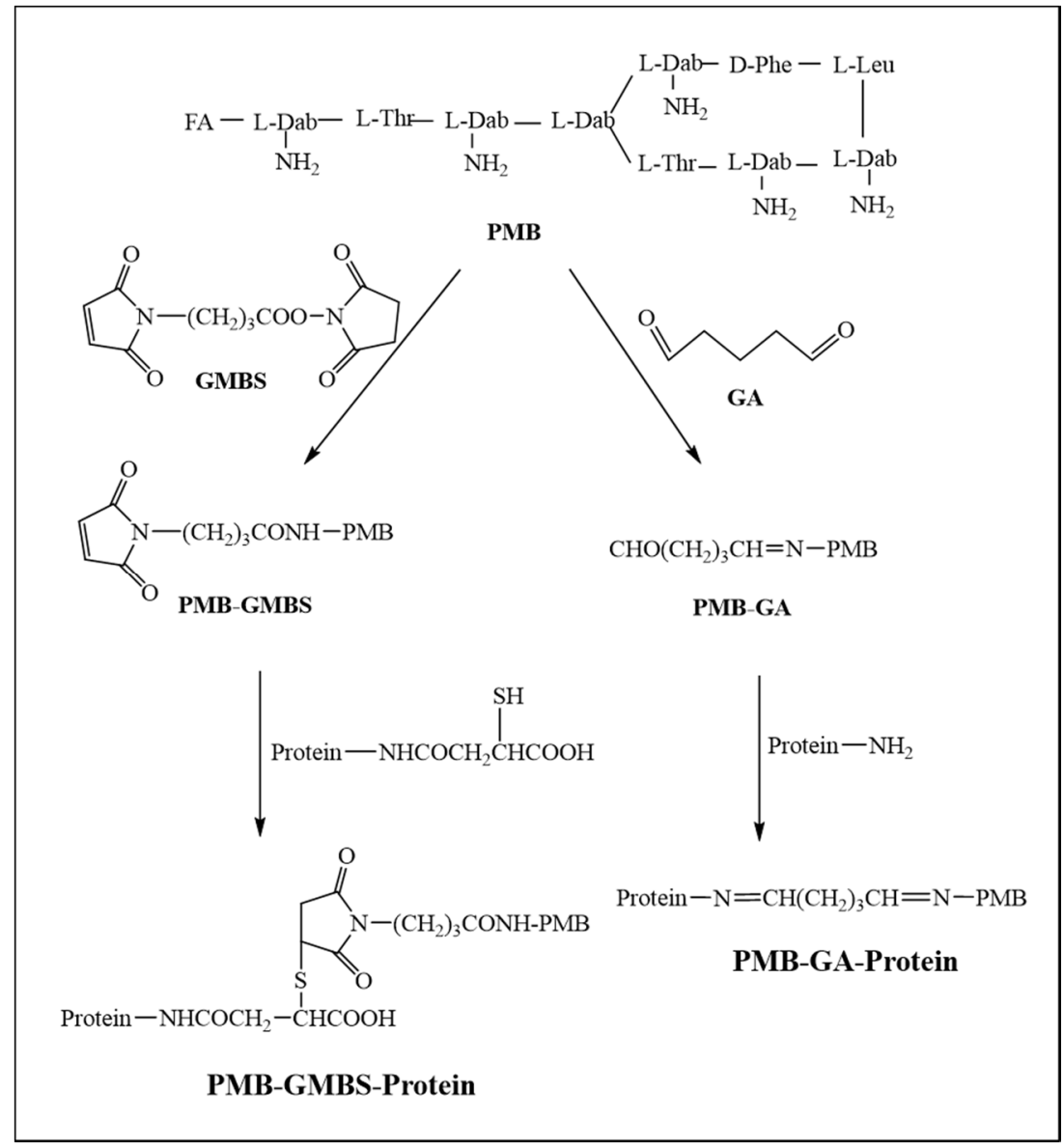

Figure 2. Conjugation of PMB to carrier proteins.

\subsection{Production and Purification of $m A b s$}

The mAbs were produced using a previously described procedure with slight modifications [29]. Female BALB/c mice (8-10 weeks of age, Qinglongshan Laboratory Animal Co., Ltd. (Nanjing, China)) were immunized with an emulsion prepared from $100 \mu \mathrm{g}$ immunogen in $100 \mu \mathrm{L}$ normal saline with an equal volume of complete Freund's adjuvant by subcutaneous multipoint injection. Four weeks after the initial injection, four booster injections were given triweekly with $50 \mu \mathrm{g}$ immunogen mixed with an equal volume of incomplete Freund's adjuvant. Finally, the mice with highest affinity and lowest $\mathrm{IC}_{50}$ to PB were given an intraperitoneal injection of $25 \mu \mathrm{g}$ immunogen in $100 \mu \mathrm{L}$ normal saline. Three days after the final injection, spleen cells were collected and fused with SP2/0 via PEG 1500 according the same procedure [23]. After three subclones, two hybridomas were raised and expanded in BALB/c mice. Finally, the mAbs were purified using the caprylic acid-ammonium sulfate method [30].

\subsection{IcELISA Procedure}

The icELISA was performed according to conventional protocols [31]. In brief, $100 \mu \mathrm{L}$ of coating antigen diluted in coating buffer (0.01 M carbonate buffer, CBS, pH 9.6) was coated in 96-well microplates. After incubating at $37{ }^{\circ} \mathrm{C}$ for $2 \mathrm{~h}$, the plates were washed three times with washing buffer $(0.05 \%(v / v)$ Tween-20 in $0.01 \mathrm{M}$ PBS) and each well was subsequently blocked with $200 \mu \mathrm{L}$ of blocking buffer $\left(0.05 \mathrm{M}\right.$ CBS containing $0.2 \%(\mathrm{~m} / \mathrm{v})$ gelatin) for $2 \mathrm{~h}$ at $37{ }^{\circ} \mathrm{C}$. Following another washing step, $50 \mu \mathrm{L}$ of a serially diluted PMB standard solution or sample solution was added to different wells, then $50 \mu \mathrm{L}$ of anti-PMB mAb was added to each well and the plates were incubated at $37^{\circ} \mathrm{C}$ for $30 \mathrm{~min}$. Similarly, $100 \mu \mathrm{L}$ of HRP-IgG was added to each well and incubated for $30 \mathrm{~min}$ at 
$37^{\circ} \mathrm{C}$ after a wash procedure. After washing four times, $100 \mu \mathrm{L}$ of TMB substrate was added to each well to react for $15 \mathrm{~min}$ at $37^{\circ} \mathrm{C}$ in darkness. Subsequently, the enzymatic reaction was stopped by the addition of $50 \mu \mathrm{L}$ of $2 \mathrm{M}$ sulfuric acid per well. The absorbances were measured at $450 \mathrm{~nm}$ with a microplate reader.

\subsection{Specificity of $m A b s$}

The antibody specificities were determined by measuring cross-reactivity (CR) with PME using the icELISA method. The CR values were calculated according to the following equation:

$$
\mathrm{CR} \%=\left(\mathrm{IC}_{50} \text { of } \mathrm{PMB}\right) /\left(\mathrm{IC}_{50} \text { of } \mathrm{PME}\right) \times 100
$$

\subsection{Preparation of AuNPs-Labeled $m A b$}

The AuNPs solution was fabricated using sodium citrate reduction method as previously described [32], with some modifications. In brief, $100 \mathrm{~mL}$ of $0.01 \%(w / v)$ chloroauric acid solution was boiled under vigorous stirring and then mixed with $2.0 \mathrm{~mL}$ of freshly prepared $1 \%(w / v)$ trisodium citrate solution. The mixture solution was stirred unceasingly until the color turned to wine-red. After boiling for a further $5 \mathrm{~min}$, the solution was cooled to room temperature and stored at $4{ }^{\circ} \mathrm{C}$ until used.

The antibody was labeled with AuNPs based on a previously described protocol [33]. Briefly, $10 \mathrm{~mL}$ of $1 \mathrm{nM}$ AuNPs solution was adjusted to $\mathrm{pH} 8.0$ with $0.1 \mathrm{M}$ potassium carbonate solution and then conjugated with the anti-PMB mAb. Following incubation at room temperature for $1 \mathrm{~h}$, the conjugates were mixed with $1 \mathrm{~mL}$ of $0.5 \%(w / v)$ BSA at room temperature for another $2 \mathrm{~h}$ to stabilize the conjugates. Subsequently, the mixture was centrifuged at $7000 \times g$ for 30 min. Finally, the resulting precipitate was washed three times with $0.02 \mathrm{M}$ phosphate buffer (containing $5 \%$ sucrose, $1 \%$ BSA and 0.5\% PEG-6000, pH 7.4), resuspended in $1 \mathrm{~mL}$ of $0.02 \mathrm{M}$ PBS containing $0.02 \% \mathrm{NaN}_{3}$ and stored at $4{ }^{\circ} \mathrm{C}$ until use.

\subsection{Construction and Principle of the Immunochromatographic Test Strip}

As shown in Figure 3, the composition of the $5 \mathrm{~cm}$ ICT strip, starting from the bottom, was as follows: the sample pad, the conjugate pad, the NC membrane and the absorbent pad [34]. The conjugate pad was sprayed with AuNPs-labeled mAb and two types of mAb were used. For the test line ( $\mathrm{T}$ line) and control line ( $\mathrm{C}$ line), coating antigen (two types of coating antigen were tested) and goat anti-mouse IgG were respectively sprayed on the NC membrane. The sample pad and absorbent pad were stuck to each end of the PVC backing card. All membranes were dried for $30 \mathrm{~min}$ at $37^{\circ} \mathrm{C}$.

In the present study, the ICT strip is performed based on a competitive reaction between the free PMB contained in the sample and the fixed coating antigen applied onto the NC membrane to combine with AuNPs-labeled mAb. Owing to capillary action, sample solution added to the sample pad migrates towards the absorption pad. If the sample is analyte-positive, AuNPs-labeled mAb binds to free PMB first during diffusion, resulting in lower AuNPs-labeled mAb triggered by the coating antigen fixed on the $\mathrm{T}$ line, ultimately leading to a lighter $\mathrm{T}$ line. As the concentration of PMB increasing, the color of the $\mathrm{T}$ line disappeared. On the contrary, if the sample is analyte-negative, AuNPs-labeled mAb only bound to coating antigen and goat anti-mouse IgG, resulting in a visible $\mathrm{T}$ line and $\mathrm{C}$ line. The $\mathrm{C}$ line should always emerge, indicating the effective assembly of the strip. 


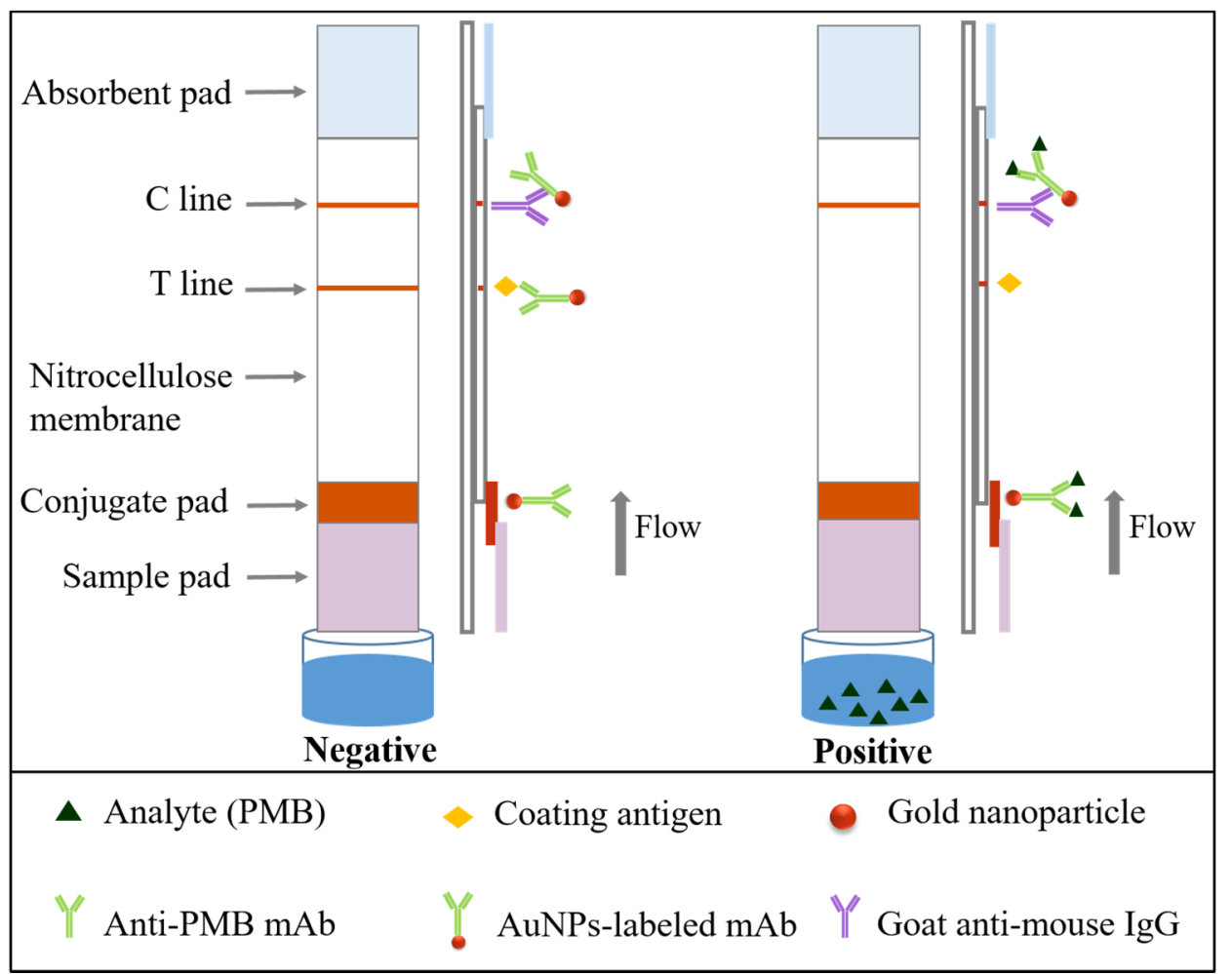

Figure 3. The scheme and principle of gold nanoparticles based immunochromatographic strip.

\subsection{Sample Analysis}

Milk and animal feed samples were analyzed using the ICT strips. All samples were confirmed as PMB negative by LC-MS/MS. The samples were then spiked with various amounts of PMB reference and the feed samples were pretreated for analysis as follows: In brief, a representative sample was first ground and mixed. Then $5.0 \mathrm{~g}$ of the ground sample was added to $25.0 \mathrm{~mL}$ of $70 \%$ methanol and vortexed vigorously for $3 \mathrm{~min}$. Following centrifugation for $5 \mathrm{~min}$ at $4000 \times \mathrm{g}$ at room temperature, $1 \mathrm{~mL}$ of the obtained supernatant was diluted with $1 \mathrm{~mL}$ of distilled water and analyzed by the ICT strip.

\section{Results and Discussion}

\subsection{Identification of Conjugates}

Confirmation of the conjugation reactions was accomplished using ultraviolet-visible (UV-vis) spectra in the range of 200-450 $\mathrm{nm}$ (Figure 4). There was no characteristic absorbance contribution of PMB, while the two carrier proteins, BSA and OVA, showed characteristic absorbance at $280 \mathrm{~nm}$. The characteristic absorbance peaks of the conjugates (PMB-GMBS-BSA, PMB-GMBS-OVA, PMB-GA-OVA1 and PMB-GA-OVA2) reached almost $375 \mathrm{~nm}$. In addition, the wider peaks at $280 \mathrm{~nm}$ were observed for all the PMB conjugates. These differences in waveforms and peak type proved that the couplings of PMB and carrier proteins were successful. 

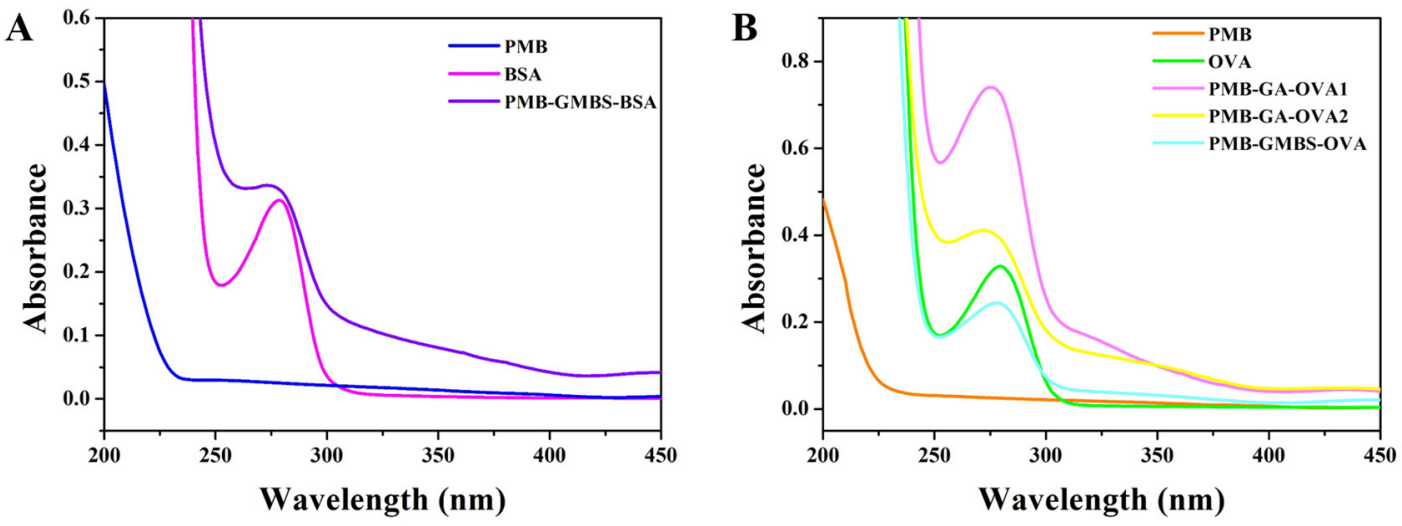

Figure 4. UV-vis spectra of BSA $(0.5 \mathrm{mg} / \mathrm{mL})$, PMB $(0.5 \mathrm{mg} / \mathrm{mL})$ and PMB-GMBS-BSA $(0.5 \mathrm{mg} / \mathrm{mL})$ (A) and (B) OVA $(0.5 \mathrm{mg} / \mathrm{mL})$, PMB $(0.5 \mathrm{mg} / \mathrm{mL})$ and the conjugates (PMB-GA-0VA1, PMB-GA-OVA2 and PMB-GMBS-OVA) $(0.5 \mathrm{mg} / \mathrm{mL})$.

\subsection{Characterization of $m A$ bs}

To select the high sensitivity antibody, three types of coating antigens, PMB-GMBS-OVA, PMB-GA-OVA1 and PMB-GA-OVA2, were tested. The inhibition rate $\left(1-\mathrm{A} / \mathrm{A}_{0}\right) * 100 \%$ was chosen to authenticate the binding ability of antibodies to $P M B$, where $A$ and $A_{0}$ were the $\mathrm{OD}_{450 \mathrm{~nm}}$ values of the PMB standard solution and blank solution, respectively.

The data indicated (not shown) that 2A2 showed low inhibition rates, irrespective of the coating antigen used. For 3C6, although homologous coating antigen (PMB-GMBS-OVA) provided higher affinity, the heterologous combination (PMB-GA-OVA1) was chosen for further investigation due to its superior inhibition compared with PMB-GA-OVA2. This may have been due to exposure of the recognition site to heterologous coating antigen [35]. The calibration curves of $2 \mathrm{~A} 2$ and $3 \mathrm{C} 6$ were then established $\left(R^{2}=0.999\right.$, Figure 5$)$. It was found that the $\mathrm{IC}_{50}$ values of the two $\mathrm{mAbs}$ were $15.26 \mathrm{ng} / \mathrm{mL}$ and $13.13 \mathrm{ng} / \mathrm{mL}$, respectively, which revealed that $3 \mathrm{C} 6$ showed higher sensitivity.

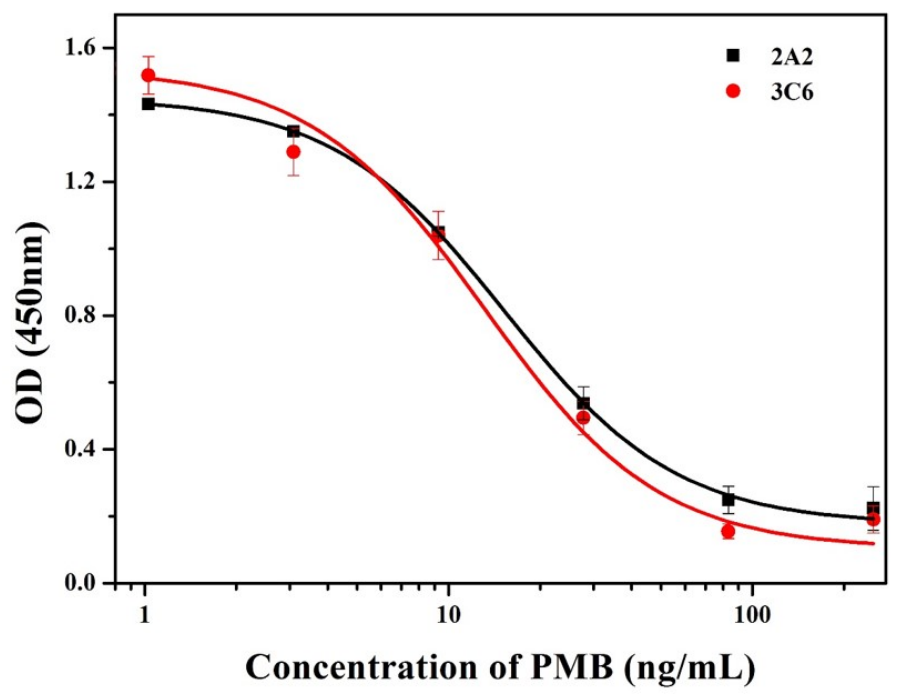

Figure 5. Calibration curves of $\mathrm{mAb} 2 \mathrm{~A} 2$ and $3 \mathrm{C} 6$.

\subsection{Specificity of $m A b s$}

By determining the CR for PME, the specificities of $2 \mathrm{~A} 2$ and $3 \mathrm{C} 6$ were assessed (Table 1). The data showed that both 2A2 and 3C6 exhibited low CR for PME, where the CR values were $5.06 \%$ for 3C6 and no $\mathrm{CR}$ was obtained for 2A2, indicating that both $2 \mathrm{~A} 2$ and $3 \mathrm{C} 6$ possessed high specificity for PMB. 
Table 1. The CR values of mAb 2A2 and 3C6 against PME by the ic-ELISA method.

\begin{tabular}{cccc}
\hline $\mathbf{m A b}$ & Analytes & $\mathbf{I C}_{\mathbf{5 0}}$ (ng/mL) & $\mathbf{C R} \mathbf{( \% )}$ \\
\hline \multirow{2}{*}{$2 \mathrm{~A} 2$} & PMB & 15.26 & $100 \%$ \\
& PME & $>1000$ & - \\
\hline \multirow{2}{*}{$3 \mathrm{C} 6$} & PMB & 13.13 & $100 \%$ \\
& PME & 259 & $5.07 \%$ \\
\hline
\end{tabular}

\subsection{Preparation of $A u N P s$}

Through electrostatic bonds, gold nanoparticles can combine with many proteins and retain their bioactivity. In present study, AuNPs with a diameter of $15 \mathrm{~nm}$ were selected because of their stability and adsorption $[33,36]$. As shown in Figure 6, the AuNPs possess predominant homogeneity and maximum absorption at $523 \mathrm{~nm}$.
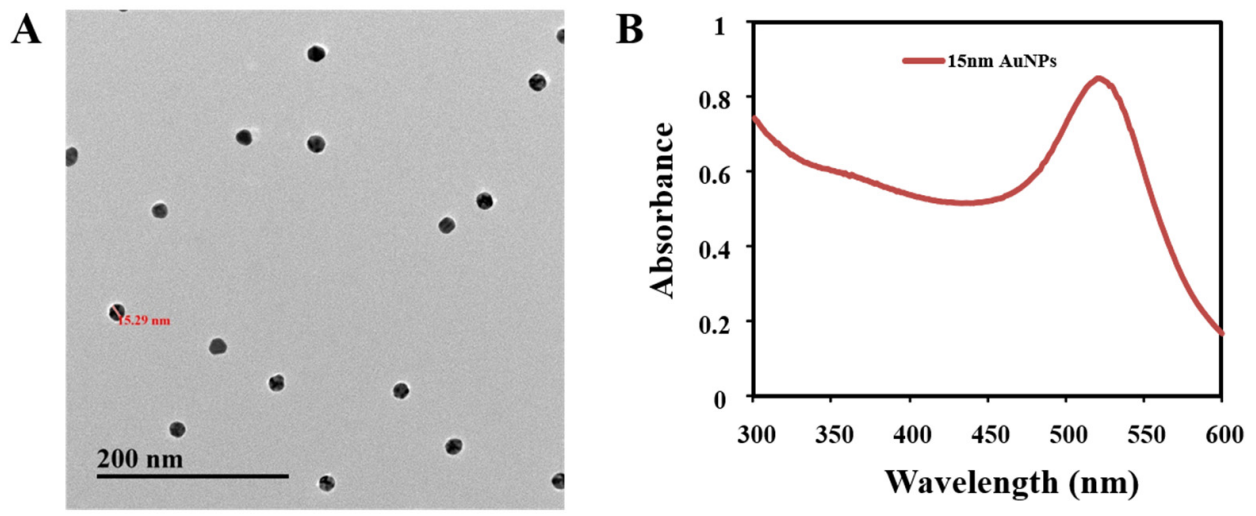

Figure 6. Characterization of the AuNPs solution: (A) transmission electron microscopy (TEM) images and (B) ultraviolet-visible (UV-vis) spectra.

\subsection{Optimization of the ICT Strip}

The sensitivity of the ICT strip largely depended on the AuNPs-labeled mAb and the coating antigen immobilized on the conjugate pad and NC membrane, respectively [37]. Therefore, two types of $\mathrm{mAb}(2 \mathrm{~A} 2$ and $3 \mathrm{C} 6)$ and coating antigens (PMB-GA-OVA1 and PMB-GA-OVA2) were compared using $0 \mathrm{ng} / \mathrm{mL}$ and $250 \mathrm{ng} / \mathrm{mL}$ of the PMB standard solution. As shown in Figure 7A, no test line was observed when mAb 2A2 was combined with PMB-GA-OVA1 or PMB-GA-OVA2, whereas a distinct test line was obtained when $3 \mathrm{C} 6$ was combined with both coating antigens. This may be explained by the lower affinity of 2A2 to both coating antigens, as an overt control line was ultimately observed. In addition, for 3C6, an appreciably deeper $C$ line using PMB-GA-OVA1 was observed, which was more beneficial for visual semi-quantitative detection. Consequently, PMB-GA-OVA1 and 3C6 were chosen as the optimal combination for further experiments.

Running buffer has an influence on the flow rate of the AuNPs-labeled mAb and therefore, the intensity of the control line [37,38]. As a consequence, different running buffers were prepared and compared by detecting PMB-negative and PMB-positive samples. The concentration of coating antigen was $0.25 \mathrm{mg} / \mathrm{mL}$. The basic buffer contained $20 \mathrm{mM}$ Tris buffer $(\mathrm{pH} 8.2), 0.1 \%(w / v)$ PEG, $0.1 \%(w / v)$ Tween-20, 5\% $(w / v)$ sucrose, $5 \%(w / v)$ trehalose and $0.2 \%(w / v)$ BSA. Other buffers included polyvinylpyrrolidone (PVP), PEG, polyvinyl alcohol (PVA), BSA, casein, sucrose, trehalose, sorbitol, mannitol, Tween-20, Brij 35, Triton X-100 and Rhodasurf ${ }^{\circledR}$ On-870 (an ethoxylated oleyl alcohol). With the exception of PVA, all buffers gave a colored control line but higher intensities were observed when Tween-20, Brij 35, Triton X-100 and On-870 were used (Figure 7B). Therefore, these four buffers were used to further optimize experiments with $0.5 \mathrm{mg} / \mathrm{mL}$ of coating antigen (Figure 7C) [36]. 
Triton X-100 contributed to a deeper $\mathrm{T}$ line and $\mathrm{C}$ line, probably due to its $\mathrm{pH}$ and ionic strength. Therefore, Triton X-100 was selected as the running buffer.

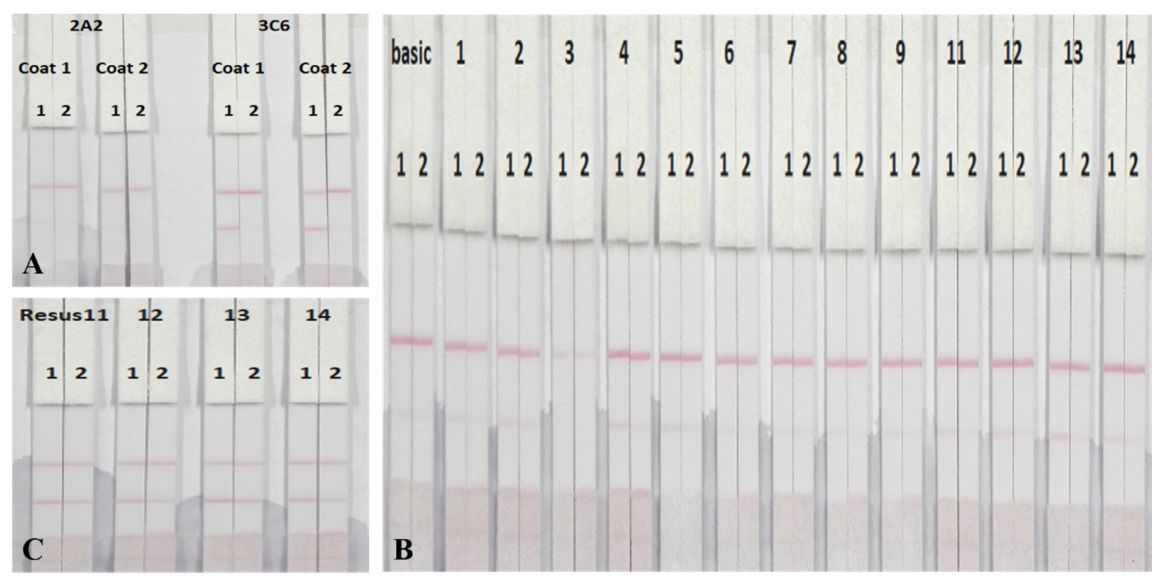

Figure 7. (A) Two kinds of AuNPs-labeled mAb with two kinds of coating antigens, respectively. Coating 1 was PMB-GA-OVA1, while coating 2 was PMB-GA-OVA2. The concentration of each coating antigen was $0.5 \mathrm{mg} / \mathrm{mL} .1=0 \mathrm{ng} / \mathrm{mL}$ and $2=250 \mathrm{ng} / \mathrm{mL}$ of PMB standards. (B) ICT strip with different running buffers. The basic buffer contained $20 \mathrm{Mm}$ Tris buffer (pH 8.2), $0.1 \%(w / v)$ PEG, $0.1 \%(w / v)$ Tween-20, $5 \%(w / v)$ sucrose, $5 \%(w / v)$ thehalose and $0.2 \%(w / v)$ BSA. Other buffers, from left to right, including PVP, PEG, PVA, BSA, casein, sucrose, thehalose, sorbitol, mannitol, tween-20, brij 35, triton X-100 and On-870. Coating (PMB-GA-OVA1) concentration was $0.25 \mathrm{mg} / \mathrm{mL} .1=0 \mathrm{ppb}$ and $2=200 \mathrm{ppb}$. (C) Different running buffer with coating (PMB-GA-OVA1) concentration of $0.5 \mathrm{mg} / \mathrm{mL}$, from left to right: tween-20, brij 35, triton X-100 and On-870. $1=0 \mathrm{ng} / \mathrm{mL}$ and $2=250 \mathrm{ng} / \mathrm{mL}$ of PMB standards. $n=6$.

\subsection{Sensitivity of the ICT Strip}

The visual limit of detection (vLOD) of the ICT strip was defined as the lowest concentration of $\mathrm{PMB}$ that resulted in a less bright $\mathrm{T}$ line compared with that of the negative samples, while the cut-off limit was defined as the threshold concentration of PMB that resulted in complete disappearance of the $\mathrm{T}$ line. Under the selected conditions, a series of concentrations of PMB reference substances in ultrapure water were analyzed using the ICT strip. As shown in Figure 8, when the concentration of PMB increased, a lighter T line was observed. Twenty-five $\mathrm{ng} / \mathrm{mL}$ of PMB generated a distinct visible difference in the color intensity of the $\mathrm{T}$ line between the sample and the blank (no PMB). Consequently, $25 \mathrm{ng} / \mathrm{mL}$ of PMB was regarded as the vLOD value. In addition, the color of the T line entirely disappeared at $100 \mathrm{ng} / \mathrm{mL}$, which revealed that $100 \mathrm{ng} / \mathrm{mL}$ of PMB was the cutoff limit. The sensitivity of the ICT strip was ideal.

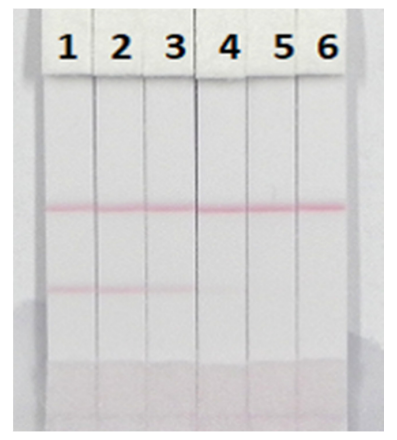

Figure 8. The sensitivity of ICT strip. $1=0 \mathrm{ng} / \mathrm{mL} ; 2=10 \mathrm{ng} / \mathrm{mL}, 3=25 \mathrm{ng} / \mathrm{mL}, 4=50 \mathrm{ng} / \mathrm{mL}$, $5=100 \mathrm{ng} / \mathrm{mL}$ and $6=250 \mathrm{ng} / \mathrm{mL}, n=6$. 


\subsection{Sample Analysis}

The performance characteristics of the ICT strip were determined by analysis of milk and animal feed samples, which were verified as PMB negative by LC-MS/MS (data not shown) and spiked with different amounts of PMB reference substances. The milk samples were spiked with PMB standard solution $(10 \mu \mathrm{g} / \mathrm{mL}$, diluted in $0.01 \mathrm{M}$ PBS, $\mathrm{pH} 7.4)$ at final concentrations of $0,1,2.5,5,10,25,50$ and $100 \mathrm{ng} / \mathrm{mL}$, while animal feed samples were spiked with PMB at concentrations of 0, 25, 50, 100, 250, 500 and $1000 \mu \mathrm{g} / \mathrm{kg}$. The spiked series was prepared on different days. In general, an ICT strip approach should be easily conducted within a limited time. Therefore, no sample preparation and a simple sample preparation procedure were required for the milk samples and animal feed samples, respectively. Each sample was analyzed six times with the optimal ICT strips. The results are presented in Figure 9 and show that the color intensity of the T line for the milk samples and animal feed samples weakened when the concentration of PMB increased until the cutoff limits were reached. Significantly weaker $\mathrm{T}$ lines compared with the negative samples were observed at $25 \mathrm{ng} / \mathrm{mL}$ for the milk samples and $500 \mu \mathrm{g} / \mathrm{kg}$ for the animal feed samples. Furthermore, $100 \mathrm{ng} / \mathrm{mL}$ and $1000 \mu \mathrm{g} / \mathrm{kg}$ of PMB were the cutoff limits for the milk samples and animal samples, respectively. Therefore, the ICT strip could be applied for the semi-quantitative detection of PMB in milk and animal feed samples.
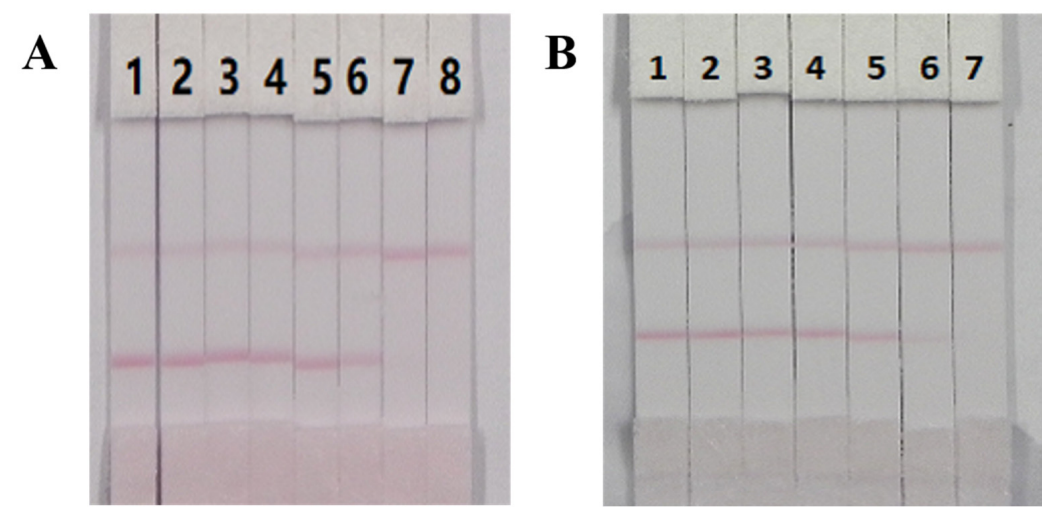

Figure 9. Analysis of samples with PMB spiking using ICT strip. Milk samples (A), $1=0 \mathrm{ng} / \mathrm{mL}$, $2=1 \mathrm{ng} / \mathrm{mL}, 3=2.5 \mathrm{ng} / \mathrm{mL}, 4=5 \mathrm{ng} / \mathrm{mL}, 5=10 \mathrm{ng} / \mathrm{mL}, 6=25 \mathrm{ng} / \mathrm{mL}, 7=50 \mathrm{ng} / \mathrm{mL}$ and $8=100 \mathrm{ng} / \mathrm{mL}$. Animal feed samples (B), $1=0 \mu \mathrm{g} / \mathrm{kg}, 2=25 \mu \mathrm{g} / \mathrm{kg}, 3=50 \mu \mathrm{g} / \mathrm{kg}, 4=100 \mu \mathrm{g} / \mathrm{kg}$, $5=250 \mu \mathrm{g} / \mathrm{kg}, 6=500 \mu \mathrm{g} / \mathrm{kg}$ and $7=1 \mu \mathrm{g} / \mathrm{kg} . n=6$.

\section{Conclusions}

Through mouse immune and cell fusion, two anti-PMB antibodies (2A2 and 3C6) were obtained, of which $3 \mathrm{C} 6$ showed high sensitivity ( $\mathrm{IC}_{50}$ value of $13.13 \mathrm{ng} / \mathrm{mL}$ ) with the heterogeneous combination of PMB-GMBS-BSA with PMB-GA-OVA1. Furthermore, 3C6 had high specificity for PMB with a CR value against PME of 5.06\%. Based on mAb 3C6, a sensitive AuNPs-based immunochromatographic strip was established for the rapid and semi-quantitative determination of PMB in milk and animal feed samples, where the vLOD values were $25 \mathrm{ng} / \mathrm{mL}$ and $500 \mu \mathrm{g} / \mathrm{kg}$, respectively and the cutoff limits were $100 \mathrm{ng} / \mathrm{mL}$ and $1000 \mu \mathrm{g} / \mathrm{kg}$, respectively. The proposed ICT strip can be used for rapid screening and semi-quantitative detection of PMB.

Acknowledgments: This work is financially supported by National Key R\&D Program (2016YFD0501208, 2016YFF0202300), the Natural Science Foundation of Jiangsu Province and MOF (BE2016307), BX20151038, BK20140003, CMB21S1614, CLE02N1515, 201513006-02, 201513006-04), the Self-determined Research Program of Jiangnan University (JUSRP51715A), and Taishan Industry Leading Talent Special Funds.

Author Contributions: Hua Kuang and Chuanlai Xu conceived and designed the experiments; Yue Li performed the experiments; Liqiang Liu, Shanshan Song analyzed the data; Yue Li wrote the first draft of the paper; all authors read and approved the manuscript prior to submission.

Conflicts of Interest: The authors declare no conflict of interest. 


\section{References}

1. Shaheen, M.; Li, J.; Ross, A.C.; Vederas, J.C.; Jensen, S.E. Paenibacillus polymyxa PKB1 produces variants of polymyxin B-type antibiotics. Chem. Biol. 2011, 18, 1640-1648. [CrossRef] [PubMed]

2. Rabanal, F.; Cajal, Y. Recent advances and perspectives in the design and development of polymyxins. Nat. Prod. Rep. 2017, 34, 886-908. [CrossRef] [PubMed]

3. Vaara, M. Novel derivatives of polymyxins. J. Antimicrob. Chemother. 2013, 68, 1213-1219. [CrossRef] [PubMed]

4. Yu, Z.; Qin, W.; Lin, J.; Fang, S.; Qiu, J. Antibacterial mechanisms of polymyxin and bacterial resistance. Biomed. Res. Int. 2015, 2015, 679109. [CrossRef] [PubMed]

5. Ryder, M.P.; Wu, X.; McKelvey, G.R.; McGuire, J.; Schilke, K.F. Binding interactions of bacterial lipopolysaccharide and the cationic amphiphilic peptides polymyxin B and WLBU2. Colloids Surf. B Biointerfaces 2014, 120, 81-87. [CrossRef] [PubMed]

6. Han, M.L.; Velkov, T.; Zhu, Y.; Roberts, K.D.; Le Brun, A.P.; Chow, S.H.; Gutu, A.D.; Moskowitz, S.M.; Shen, H.H.; Li, J. Polymyxin-Induced Lipid A Deacylation in Pseudomonas aeruginosa Perturbs Polymyxin Penetration and Confers High-Level Resistance. ACS Chem. Biol. 2018, 13, 121-130. [CrossRef] [PubMed]

7. Justo, J.A.; Bosso, J.A. Adverse reactions associated with systemic polymyxin therapy. Pharmacotherapy 2015, 35, 28-33. [CrossRef] [PubMed]

8. Kadar, B.; Kocsis, B.; Nagy, K.; Szabo, D. The Renaissance of Polymyxins. Curr. Med. Chem. 2013, 20, $3759-3773$. [CrossRef] [PubMed]

9. Bergen, P.J.; Landersdorfer, C.B.; Lee, H.J.; Li, J.; Nation, R.L. 'Old' antibiotics for emerging multidrug-resistant bacteria. Curr. Opin. Infect. Dis. 2012, 25, 626-633. [CrossRef] [PubMed]

10. Velkov, T.; Roberts, K.D.; Nation, R.L.; Thompson, P.E.; Li, J. Pharmacology of polymyxins: New insights into an 'old' class of antibiotics. Future Microbiol. 2013, 8, 711-724. [CrossRef] [PubMed]

11. Garg, S.K.; Singh, O.; Juneja, D.; Tyagi, N.; Khurana, A.S.; Qamra, A.; Motlekar, S.; Barkate, H. Resurgence of Polymyxin B for MDR/XDR Gram-Negative Infections: An Overview of Current Evidence. Crit. Care Res. Pract. 2017, 2017, 3635609. [CrossRef] [PubMed]

12. Liu, Y.Y.; Wang, Y.; Walsh, T.R.; Yi, L.-X.; Zhang, R.; Spencer, J.; Doi, Y.; Tian, G.; Dong, B.; Huang, X.; et al. Emergence of plasmid-mediated colistin resistance mechanism MCR-1 in animals and human beings in China a microbiological and molecular biological study. Lancet Infect. Dis. 2016, 16, 161-168. [CrossRef]

13. Olaitan, A.O.; Morand, S.; Rolain, J.M. Mechanisms of polymyxin resistance: Acquired and intrinsic resistance in bacteria. Front. Microbiol. 2014, 5, 643. [CrossRef] [PubMed]

14. Jeannot, K.; Bolard, A.; Plesiat, P. Resistance to polymyxins in Gram-negative organisms. Int. J. Antimicrob. Agents 2017, 49, 526-535. [CrossRef] [PubMed]

15. Sitzlar, B.; Vajravelu, R.K.; Jury, L.; Donskey, C.J.; Jump, R.L. Environmental decontamination with ultraviolet radiation to prevent recurrent Clostridium difficile infection in 2 roommates in a long-term care Facility. Infect. Control Hosp. Epidemiol. 2012, 33, 534-536. [CrossRef] [PubMed]

16. Tam, V.H.; Cao, H.; Ledesma, K.R.; Hu, M. In vitro potency of various polymyxin B components. Antimicrob. Agents Chemother. 2011, 55, 4490-4491. [CrossRef] [PubMed]

17. Covelli, J.; Ruszaj, D.; Straubinger, R.; Li, J.; Rao, G.G. The development and validation of a simple liquid chromatography-tandem mass spectrometry method for polymyxin B1 and B2 quantification in different matrices. J. Chromatogr. B Anal. Technol. Biomed. Life Sci. 2017, 1065-1066, 112-118. [CrossRef] [PubMed]

18. Meng, M.; Wang, L.; Liu, S.; Jaber, O.M.; Gao, L.; Chevrette, L.; Reuschel, S. Simultaneous quantitation of polymyxin B1, polymyxin B2 and polymyxin B1-1 in human plasma and treated human urine using solid phase extraction and liquid chromatography-tandem mass spectrometry. J. Chromatogr. B Anal. Technol. Biomed. Life Sci. 2016, 1012-1013, 23-36. [CrossRef] [PubMed]

19. Hee, K.H.; Leaw, Y.K.J.; Ong, J.L.; Lee, L.S. Development and validation of liquid chromatography tandem mass spectrometry method quantitative determination of polymyxin B1, polymyxin B2, polymyxin B3 and isoleucine-polymyxin B1 in human plasma and its application in clinical studies. J. Pharm. Biomed. Anal. 2017, 140, 91-97. [CrossRef] [PubMed]

20. Cheah, S.E.; Bulitta, J.B.; Li, J.; Nation, R.L. Development and validation of a liquid chromatography-mass spectrometry assay for polymyxin B in bacterial growth media. J. Pharm. Biomed. Anal. 2014, 92, 177-182. [CrossRef] [PubMed] 
21. Saita, T.; Yoshida, M.; Nakashima, M.; Matsunaga, H.; Fujito, H.; Mori, M. A high sensitive ELISA for the quantification of polymyxin B sulfate in Human serum. Biol. Pharm. Bull. 1999, 22, 1257-1261. [CrossRef] [PubMed]

22. Bulbul, G.; Hayat, A.; Andreescu, S. Portable Nanoparticle-Based Sensors for Food Safety Assessment. Sensors 2015, 15, 30736-30758. [CrossRef] [PubMed]

23. Peng, J.; Liu, L.L.; Xu, L.G.; Song, S.S.; Kuang, H.; Cui, G.; Xu, C.L. Gold nanoparticle-based paper sensor for ultrasensitive and multiple detection of 32 (fluoro) quinolones by one monoclonal antibody. Nano Res. 2016, 10, 108-120. [CrossRef]

24. Omidfar, K.; Khorsand, F.; Azizi, M.D. New analytical applications of gold nanoparticles as label in antibody based sensors. Biosens. Bioelectron. 2013, 43, 336-347. [CrossRef] [PubMed]

25. Fang, C.; Dharmarajan, R.; Megharaj, M.; Naidu, R. Gold nanoparticle-based optical sensors for selected anionic contaminants. TrAC Trends Anal. Chem. 2017, 86, 143-154. [CrossRef]

26. Yoo, J.H.; Woo, D.H.; Chang, M.S.; Chun, M.S. Microfluidic based biosensing for Escherichia coli detection by embedding antimicrobial peptide-labeled beads. Sens. Actuators B Chem. 2014, 191, 211-218. [CrossRef]

27. Chen, Y.; Liu, L.; Song, S.; Kuang, H.; Xu, C. Establishment of a monoclonal antibody-based indirect enzyme-linked immunosorbent assay for the detection of trimethoprim residues in milk, honey and fish samples. Food Agric. Immunol. 2016, 27, 830-840. [CrossRef]

28. Xu, F.; Jiang, W.; Zhou, J.; Wen, K.; Wang, Z.; Jiang, H.; Ding, S. Production of Monoclonal Antibody and Development of a New Immunoassay for Apramycin in Food. J. Agric. Food Chem. 2014, 62, 3108-3113. [CrossRef] [PubMed]

29. Uchigashima, M.; Watanabe, E.; Ito, S.; Iwasa, S.; Miyake, S. Development of immunoassay based on monoclonal antibody reacted with the neonicotinoid insecticides clothianidin and dinotefuran. Sensors 2012, 12, 15858-15872. [CrossRef] [PubMed]

30. Kuang, H.; Xing, C.; Hao, C.; Liu, L.; Wang, L.; Xu, C. Rapid and highly sensitive detection of lead ions in drinking water based on a strip immunosensor. Sensors 2013, 13, 4214-4224. [CrossRef] [PubMed]

31. Kong, N.; Song, S.; Peng, J.; Liu, L.; Kuang, H.; Xu, C. Sensitive, fast and specific immunoassays for methyltestosterone detection. Sensors 2015, 15, 10059-10073. [CrossRef] [PubMed]

32. Sun, F.; Liu, L.; Ma, W.; Xu, C.; Wang, L.; Kuang, H. Rapid on-site determination of melamine in raw milk by an immunochromatographic strip. Int. J. Food Sci. Technol. 2012, 47, 1505-1510. [CrossRef]

33. Peng, J.; Wang, Y.; Liu, L.; Kuang, H.; Li, A.; Xu, C. Multiplex lateral flow immunoassay for five antibiotics detection based on gold nanoparticle aggregations. RSC Adv. 2016, 6, 7798-7805. [CrossRef]

34. Zhou, C.; Zhang, X.; Huang, X.; Guo, X.; Cai, Q.; Zhou, S. Rapid Detection of Chloramphenicol Residues in Aquatic Products Using Colloidal Gold Immunochromatographic Assay. Sensors 2014, 14, 21872-21888. [CrossRef] [PubMed]

35. Jiang, J.; Zhang, H.; An, Z.; Xu, Z.; Yang, X.; Huang, H.; Wang, Z. Development of an Heterologous Immunoassay for Ciprofloxacin Residue in Milk. Phys. Procedia 2012, 25, 1829-1836. [CrossRef]

36. Kong, D.; Liu, L.; Song, S.; Suryoprabowo, S.; Li, A.; Kuang, H.; Wang, L.; Xu, C. A gold nanoparticle-based semi-quantitative and quantitative ultrasensitive paper sensor for the detection of twenty mycotoxins. Nanoscale 2016, 8, 5245-5253. [CrossRef] [PubMed]

37. Kong, D.; Liu, L.; Song, S.; Zheng, Q.; Wu, X.; Kuang, H. Rapid detection of tenuazonic acid in cereal and fruit juice using a lateral-flow immunochromatographic assay strip. Food Agric. Immunol. 2017, 28, 1293-1303. [CrossRef]

38. Foubert, A.; Beloglazova, N.V.; Gordienko, A.; Tessier, M.D.; Drijvers, E.; Hens, Z.; De Saeger, S. Development of a Rainbow Lateral Flow Immunoassay for the Simultaneous Detection of Four Mycotoxins. J. Agric. Food Chem. 2017, 65, 7121-7130. [CrossRef] [PubMed]

(C) 2018 by the authors. Licensee MDPI, Basel, Switzerland. This article is an open access article distributed under the terms and conditions of the Creative Commons Attribution (CC BY) license (http:/ / creativecommons.org/licenses/by/4.0/). 